\title{
Progressive programmed cell death inwards across the anther wall in male sterile flowers of the gynodioecious plant Plantago lanceolata
}

\author{
Jacqueline M. Nugent ${ }^{1} \cdot$ Tómas Byrne $^{1} \cdot$ Grace McCormack $^{1} \cdot$ Marc Quiwa $^{1} \cdot$ Elaine Stafford $^{1}$
}

Received: 24 August 2018 / Accepted: 15 November 2018 / Published online: 27 November 2018

c) Springer-Verlag GmbH Germany, part of Springer Nature 2018

\begin{abstract}
Main conclusion A cell death signal is perceived and responded to by epidermal cells first before being conveyed inwards across the anther wall in male sterile Plantago lanceolata flowers.

In gynodioecious plants, floral phenotype is determined by an interplay between cytoplasmic male sterility (CMS)-promoting factors and fertility-restoring genes segregating in the nuclear background. Plantago lanceolata exhibits at least four different sterilizing cytoplasms. MS1, a "brown-anther" male sterile phenotype, segregates with a CMSI cytoplasm and a non-restoring nuclear background in P. lanceolata populations. The aim of this study was to investigate the cytology of early anther development in segregating hermaphrodite and male sterile flowers sharing the same CMSI cytoplasm, and to determine if the sterility phenotype correlates with any changes to the normal pattern of programmed cell death (PCD) that occurs during anther development. Cytology shows cellular abnormalities in all four anther wall layers (epidermis, endothecium, middle layer and tapetum), the persistence and enlargement of middle layer and tapetal cells, and the failure of microspore mother cells to complete meiosis in male sterile anthers. In these anthers, apoptotic-PCD occurs earlier than in fertile anthers and is detected in all four cell layers of the anther wall before the middle layer and tapetal cells become enlarged. PCD is separated spatially and temporally within the anther wall, occurring first in epidermal cells before extending radially to cells in the inner anther wall layers. This is the first evidence of a cell death signal being perceived and responded to by epidermal cells first before being conveyed inwards across the anther wall in male sterile plants.
\end{abstract}

Keywords Anther development · Cell death signaling · Cytoplasmic male sterility · Epidermis · Gynodioecy · Tapetum · TUNEL

\section{Abbreviations \\ CMS Cytoplasmic male sterility \\ $\mathrm{H} \quad$ Hermaphrodite \\ MMC Microspore mother cells}

Jacqueline M. Nugent

jackie.nugent@mu.ie

Tómas Byrne

tmsbyrne7@gmail.com

Grace McCormack

gracemccormack7@gmail.com

Marc Quiwa

marcquiwa@gmail.com

Elaine Stafford

staffoel@tcd.ie

1 Department of Biology, Maynooth University, National University of Ireland Maynooth, Maynooth, Co. Kildare, Ireland $\begin{array}{ll}\text { MS } & \text { Male sterile } \\ \text { PCD } & \text { Programmed cell death }\end{array}$

\section{Introduction}

Gynodioecy is a plant breeding system where female plants (male sterile flowers) and hermaphrodite plants (flowers with fertile male and female organs) co-occur in natural populations, and is found in about $2 \%$ of angiosperm genera (Dufaÿ et al. 2014; Renner 2014). The floral phenotype is determined by cytoplasmic and nuclear gene interactions, i.e. cytoplasmic male-sterilizing genes and nuclear male fertility restorer loci (reviewed by Touzet 2012). Cytoplasmic/ nuclear gene interactions also determine cytoplasmic male sterility (CMS) in hybrid crop lines obtained from intra- or inter-specific sexual crosses where the nucleus of one accession or species is combined with the cytoplasm of another 
(Kim and Zhang 2018). CMS in these instances is associated with mitochondrial sterility genes that code for proteins that interfere with normal mitochondrial function in the absence of any counteracting fertility restoration capacity in the nucleus particularly during anther development. Many mitochondrial sterility genes and nuclear restorer genes have been identified in these hybrid crop contexts (Horn et al. 2014; Hu et al. 2014; Kim and Zhang 2018) and current models for gynodioecy propose similar mitochondrialnuclear gene interactions (Touzet 2012).

Most mitochondrial sterility genes are comprised of chimeric open reading frames (ORFs) that include pieces of known mitochondrial genes or ORFs, or are truncated copies of duplicate mitochondrial genes, or are ORFs of unknown provenance (Chen and Liu 2014; Kim and Zhang 2018). Sterility proteins are thought to affect mitochondrial function in a variety of ways including: (i) disrupting inner membrane integrity, leading to proton leakage and reduced ATP production, (ii) serving as dysfunctional components of the mitochondrial electron transfer chain or F1Fo-ATPase complexes also leading to reduced ATP production, (iii) altering retrograde signaling from the mitochondria to the nucleus, and (iv) altering peroxide metabolism and reactive oxygen species (ROS) production. Normal pollen development depends on cooperative interactions between sporophytic tissue (anther wall) and gametophytic tissue (microspores) and requires the precise regulation of $\mathrm{PCD}$ and disintegration of the tapetum, the innermost cell layer of anther wall tissue (Parish and Li 2010). Targeted expression of mitochondrial protein fragments in the mitochondria of tapetal cells inhibits the biogenesis of the electron transfer chain machinery and is sufficient to induce male sterility phenotypes in transgenic tobacco plants (Shaya et al. 2012).

Tapetal breakdown shares many of the hallmarks associated with apoptosis-like PCD including relatively rapid cell death, cell condensation and shrinkage, chromatin condensation, DNA fragmentation and eventually mitochondrial and cytoskeletal disintegration (Balk and Leaver 2001; Parish and $\mathrm{Li}$ 2010). Tapetal cell death is tightly controlled during normal pollen development and both premature and delayed tapetal PCD has been shown to lead to male sterility in many instances (Papini et al. 1999; Kawanabe et al. 2006; Ji et al. 2013). The effects of mitochondrial-encoded sterility genes on pollen development can be counteracted by nuclearencoded restorer of fertility $(R f)$ genes. $R f$ gene products are functionally quite disparate in their nature suggesting that many routes to male fertility restoration can be used by flowering plants. Most of the identified $R f$ genes code for pentatricopeptide repeat (PPR)-containing proteins that suppress mitochondrial-encoded sterility gene expression at the post-transcriptional level via a range of RNA processing mechanisms (RNA editing, splicing, polyadenylation, and/ or cleavage; Kim and Zhang 2018). It is still not clear how some other known $\mathrm{Rf}$ proteins might restore fertility, e.g. an aldehyde dehydrogenase in T-CMS in maize (Cui et al. 1996), an acyl-carrier protein synthase-like protein in CWCMS in rice (Fujii and Toriyama 2009), a putative peptidase in Owen-CMS in sugar beet (Matsuhira et al. 2012), and a glycine-rich protein in LD-CMS in rice (Itabashi et al. 2011). Some yet to be identified $R f$ genes suppress sterility gene expression at the translational and post-translational level (Landgren et al. 1996; Sarria et al. 1998; Luo et al. 2013) and others are involved in suppressing sterility gene copy number (Feng et al. 2009; Onodera et al. 2015).

It is clear that CMS in crop species is a relevant model for understanding the nuclear-cytoplasmic interplay underlying gynodioecy (Städler and Delph 2002). However, very little is known about the molecular action of mitochondrial sterility factors or nuclear restorer alleles in natural populations of non-agricultural plant species exhibiting this breeding system. Only two mitochondrial CMS genes have been identified in natural gynodioecious populations, orf 138 in wild radish and orf 129 in wild beet, and both of these were first identified in radish and sugar beet crop breeding programs (Murayama et al. 2004; Yamamoto et al. 2008). Several mitochondrial ORFs, as well as a non-coding mitochondrial RNA, have been associated with CMS in the model gynodioecious species Silene vulgaris (Sloan et al. 2012; Štorchová et al. 2012; Stone et al. 2017). No nuclear $R f$ genes have been identified in any naturally occurring gynodioecious species. Some studies have focused on the cytology of anther development in female flowers in gynodioecious plants (Moon and Hong 2015; Naghloo and Classen-Bockhoff 2016; Koch et al. 2018); however, no studies have assessed PCD during anther development in any gynodioecious species to date.

Plantago lanceolata is a gynodioecious plant species that exhibits at least four different sterilizing cytoplasms (CMSI, CMSIIa, CMSIIb and CMSIII) each associated with specific, but as yet unidentified, sterility genes (de Haan et al. 1997a). MS1, previously described as the "brown-anther" male sterile phenotype, segregates with a CMSI cytoplasm and a nonrestoring nuclear background in Plantago populations (Van Damme and Van Delden 1982). MS1 is the most frequent male sterile type found throughout the world in natural populations and genetic association studies (mitochondrial and plastid) have shown that this is because of migration and not because of recurrent mutation (de Haan et al. 1997b). The aim of this study was to investigate the effect of the CMSI cytoplasm on anther and pollen development in P. lanceolata flowers. Light microscopy was used to compare the cytology of early anther development in segregating hermaphrodite (H) and male sterile (MS) flowers sharing the CMSI cytoplasm, and in situ TdT-mediated dUTP nick-end labeling (TUNEL) assays were used to investigate if the sterility phenotype correlates with any changes to the normal pattern of PCD that occurs during anther development in P. lanceolata. 


\section{Materials and methods}

\section{Plant material}

Plants were grown from seed provided by Prof. Kirsten Wolff, Newcastle University, UK. The seed was generated by crossing an MS female parent with a hermaphrodite male parent (Cross B: NPZH 22-9 X FREQ 1-13) which results in a 1:1 segregating population of $\mathrm{H}$ and MS plants. All of the plants in the population have the same CMSI cytoplasm. The plants were grown in a greenhouse under long-day conditions (16-h light, 8-h dark) to induce and maintain flowering.

\section{Phenotypic analysis}

$\mathrm{H}$ and MS flowers of different developmental stages were examined closely using a Leica ES2 stereo microscope. Individual flowers were photographed using an Olympus SP-100 camera equipped with a superzoom lens.

\section{Cytology}

Flowers were collected from along the entire length of well-developed $\mathrm{H}$ and MS inflorescences; four to five flowers were collected together at a time to create an approximate series of flowers of different ages. The oldest flowers (just prior to anthesis) were collected from the bottom of an inflorescence and the youngest from the top. The flowers were fixed in 4\% paraformaldehyde in PBS (1\% Triton, $0.1 \%$ Tween, and $10 \%$ DMSO) by vacuum infiltration, dehydrated in a graded ethanol series, embedded in Epon epoxy resin (TAAB 812$)$ and sectioned (1- $\mu \mathrm{M}$ transverse sections) using a Leica UC6 ultramicrotome. Flower sections were stained with $1 \%$ toluidine blue, and were viewed and photographed using an Olympus BX51 microscope and an Olympus XC30 camera.

\section{Cell death assay}

Whole inflorescences were fixed in 4\% paraformaldehyde in PBS (1\% Triton, $0.1 \%$ Tween, and $10 \%$ DMSO) by vacuum infiltration, dehydrated in a graded ethanol series, embedded in paraffin wax (Paraplast X-TRA, Sigma) and sectioned $(10 \mu \mathrm{M})$ using a Leica RM2135 rotary microtome. The sections were deparaffinized with $100 \%$ Histoclear (Fisher Scientific), dehydrated in a graded ethanol series, and permeabilized in proteinase K. DNA fragmentation was assayed for using the DeadEnd Fluorometric TUNEL system (Promega) according to the manufacturer's instructions. Some sections were treated with DNaseI to induce DNA fragmentation as an experimental positive control. The assayed sections were counterstained with $1 \mu \mathrm{g} / \mathrm{mL}$ of propidium iodide and mounted with SlowFade Gold antifade reagent (Invitrogen). Cover slips were sealed and the samples were examined under an Olympus FV 1000 confocal microscope using excitation at $488 \mathrm{~nm}$ and emission at $500-530 \mathrm{~nm}$ to view the green fluorescence of fluorescein, and 543-nm excitation and 560-655-nm emission to view the red fluorescence of propidium iodide. Merged images were generated using the Olympus FluoView software. Additional sections $(10 \mu \mathrm{M})$ were stained only with $1 \%$ toluidine blue to help stage the TUNEL assay sections.

\section{Results}

\section{$H$ and MS flower phenotypes}

Hermaphrodite Plantago plants produce small protogynous flowers (stigmas are exserted and become receptive before the stamens emerge) in very condensed inflorescences at the tips of long leafless scapes (Fig. 1a, b). Flowers have four sepals, four petals that are fused to form a corolla tube, four stamens and a single pistil of two fused carpels (Fig. 1c; Henderson 1926). Before anthesis, the elongated stamen filaments are folded over and the stamens remain completely enclosed within the corolla tube. When female flowering is nearly complete, the oldest flowers at the base of the inflorescence open (the tips of the petals fold back) and exsert the elongated stamens to release pollen (Fig. 1c). Male flowering then proceeds up the inflorescence (Fig. 1a, b). Flower development in MS plants is similar to that described above except mostly with regard to stamen development. In MS flowers, stamen filaments never elongate to fold back on themselves within the corolla, and at anthesis brown, pollenless, anthers barely extend beyond the petals (Fig. 1d-f). Young developing anthers are yellowish-green and the locules develop but do not enlarge beyond a certain point, in fact they deflate and quickly turn brown (Fig. 1e, f). MS anthers do not contain any pollen. MS flowers also produce longer styles than hermaphrodites which may be a strategy to enhance female reproductive capacity (Fig. 1d-f; Olff et al. 1989).

\section{Cytological analysis of anther development}

Transverse sections of $\mathrm{H}$ flowers were analyzed to determine the progression of cellular events involved in fertile anther development in Plantago and representative stages are shown in Fig. 2. The cytology of anther development in $\mathrm{H}$ flowers is very similar to that previously described for Arabidopsis and the same numbering of early anther development stages is used in this study (Sanders et al. 1999; Scott et al. 2004). The early stages of anther development 


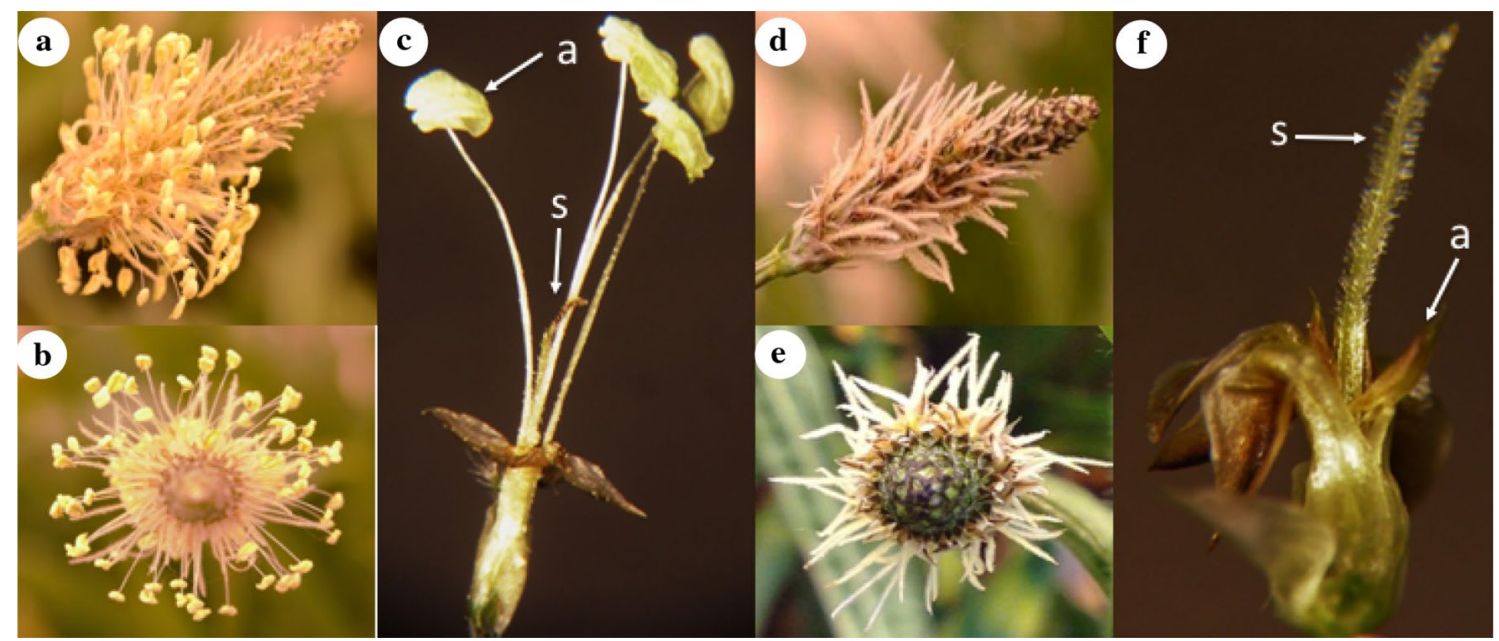

Fig. 1 Hermaphrodite and male sterile inflorescences and flowers of Plantago lanceolata. a Side view of a hermaphrodite inflorescence. b Top view of a hermaphrodite inflorescence. c Single hermaphrodite

generate microspore mother cells (MMCs) surrounded by a four-layered locule wall (epidermis, endothecium, middle layer and tapetum) after which the sporophytic tissue shows preparation for meiosis (Fig. 2a, b; anther stage 5). When diploid MMCs enter meiosis (meiocytes), the middle layer becomes crushed and degenerates, and the tapetal cells start to enlarge and become more vacuolated (Fig. 2c, d; anther stage 6). Meiosis results in tetrads of haploid microspores within each locule (Fig. 2e; anther stage 7) and after individual microspores are released the tapetal cells begin to degenerate (Fig. 2f; anther stage 8). As microspores undergo mitotic division, the tapetal cell layer is completely eliminated and the cells of the endothecium begin to enlarge (Fig. 2g, h; anther stage 11). During the final stages of pollen development, the anthers become bilocular (the septum between each pair of locules breaks down), and eventually the stomium ruptures and mature pollen grains are released (Fig. 2i; anther stage 13).

Transverse sections of MS flowers show that the early stages of anther development generate MMCs and a four-layered locule wall (epidermis, endothecium, middle layer and tapetum, Fig. 3a). However, cytological changes in anther wall cells are evident as soon as the four cell layers differentiate (stage 5); in particular, tapetal cells are larger and more vacuolated (Fig. 3a) than same stage cells in hermaphrodites (Fig. 2a). By late stage 5 onwards, tapetal cells are highly vacuolated and greatly hypertrophied; middle layer, endothecial and epidermal cells are also vacuolated but not to the same extent as tapetal cells (Fig. 3b). The middle layer cells persist and enlarge rather than being crushed and eliminated. Within the anther locules, MMCs show some preparation for meiosis in that cell staining becomes less dense and each MMC becomes more separated (Fig. 3b). flower (sepals removed). d Side view of a male sterile inflorescence. e Top view of a male sterile inflorescence. $\mathbf{f}$ Single male sterile flower (sepals removed). $a$ anther, $s$ stigma

However, the cytoplasm of these cells contains many small vacuoles not present in same stage hermaphrodite MMCs and prophase I chromosome condensation is not seen. This suggests that meiosis either does not begin in MS anthers or is disrupted very early on in the process. Only defective meiotic products accumulate within locules and these become progressively crushed by the enlarging middle layer and tapetal cells of the anther wall (Fig. 3c-e). The mature anther is indehiscent, empty, and shriveled with only the epidermal layer persisting (Fig. 3f).

\section{PCD during anther development}

In $\mathrm{H}$ anthers, the tapetal cell layer is completely degraded by the time haploid microspores commence mitosis, whereas in MS anthers a very hypertrophied tapetal cell layer persists as defective meiotic products accumulate and then become crushed within locules. This differing cytology suggested that the timing of tapetal cell death is disrupted in MS anthers by the CMSI cytoplasm. DNA fragmentation is a hallmark of apoptosis-like PCD, and TUNEL assays were performed to investigate this aspect of the cell death process in $\mathrm{H}$ and MS developing anthers. Analysis of $\mathrm{H}$ anthers shows that DNA fragmentation is not observed in any anther cells prior to MMCs entering meiosis (Fig. 4a-f; anther stage 5). DNA fragmentation is first seen in tapetal cells during meiosis (Fig. 4g-l; anther stage 6) and is still detectable up until tetrads are formed and tapetal cell wall breakdown begins (Fig. 4m-r; anther stage 7). Cells in the other three anther wall layers (epidermis, endothecium and middle layer) exhibit no DNA fragmentation at these early stages of anther development. DNA fragmentation occurs in some meiocytes and microspores during the normal process 


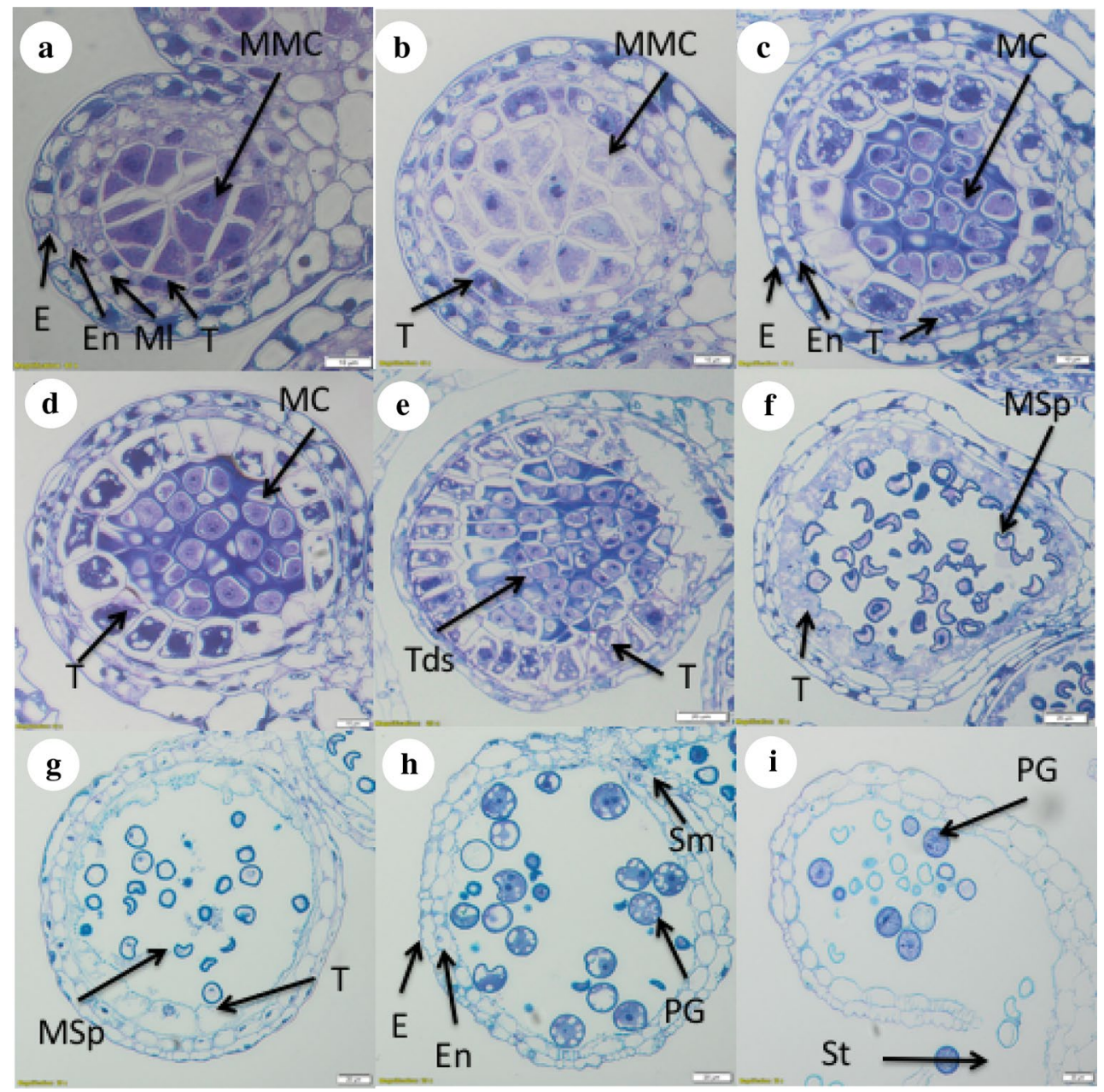

Fig. 2 Anther development in Plantago lanceolata hermaphrodite flowers. 1- $\mu \mathrm{m}$-thick transverse sections of fixed individual flowers were stained with toluidine blue and photographed under bright field microscopy. Single locules from representative stages of anther development are shown. a, b Locules are formed, microspore mother cells are formed, and four anther wall layers are present (stage 5 of anther development). c, $\mathbf{d}$ Tapetal cells become vacuolated and microspore mother cells enter meiosis (stage 6 of anther development). e Meiosis is completed and the tapetal cell wall begins to break down (stage 7 of anther development). f Haploid microspores are released and the

of pollen development (Fig. 4l, r). This is not unheard of; in barley (Hordeum vulgare) DNA fragmentation is also detected in uninucleate microspores during vacuolization (Wang et al. 1999). Nuclear DNA fragmentation was not investigated at later stages of $\mathrm{H}$ anther development, e.g. during anther dehiscence.

In situ TUNEL assays show that DNA fragmentation occurs earlier in MS anther wall cells, is first detected in the anther before MMCs show preparation for meiosis (Fig. 5; anther stage 5), and is not confined to just the tapetum but is observed in all four cell layers of the anther wall (epidermis, endothecium, middle layer and tapetum; tapetal cell wall continues to degenerate (stage 8 of anther development). g, h Pollen mitotic divisions occur, the tapetum completely degenerates and the endothecium cells expand (stage 11 of anther development). i Dehiscence, the anther wall breaks at the stomium and pollen is released (stage 13 of anther development). $E$ Epidermis, $E n$ endothecium, $M C$ meiotic cell or meiocyte, $M M C$ microspore mother cell, $M l$ middle layer, $M S p$ microspore, $P G$ pollen grain, $S t$ stomium, $T$ tapetum, $T d s$ tetrads. Scale bar $=10 \mu \mathrm{m}(\mathbf{a}-\mathbf{d}), 20 \mu \mathrm{m}$ $(\mathbf{e}-\mathbf{i})$

Fig. 5a). Because Plantago flowers are produced in such compact inflorescences (Fig. 1a, d), each tissue section contains an approximate developmental series of flower (anther) sections. A close examination of a short series of MS anther sections indicates that the initiation of PCD is separated spatially and temporally within the anther wall, occurring first in epidermal cells before progressively reaching the innermost anther wall layers (Fig. 5b-e). Thus, before any tapetal or middle cell enlargement becomes obvious in the MS anther, DNA fragmentation has occurred and PCD has commenced in all four cell layers of the anther wall. 


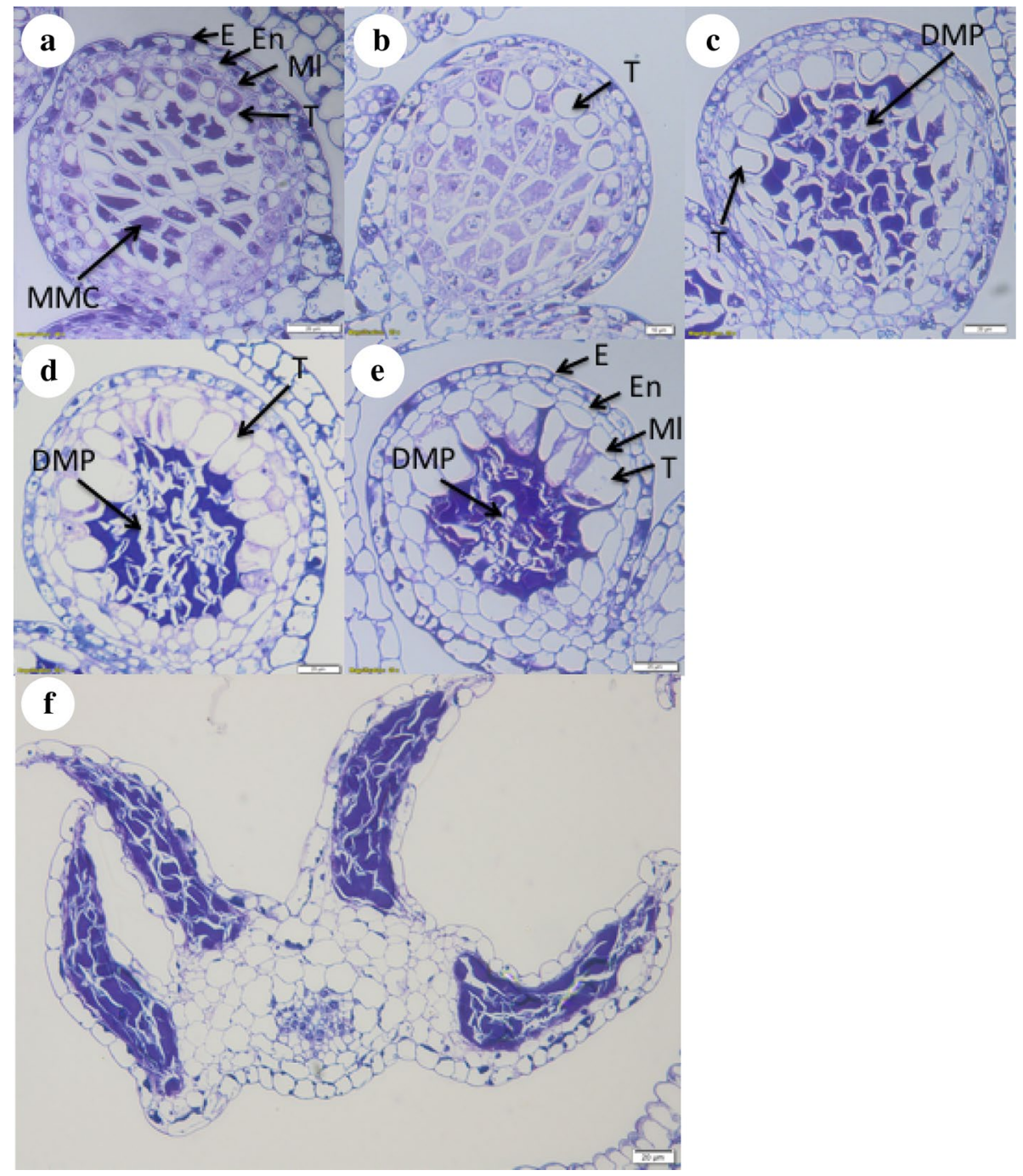

Fig. 3 Anther development in male sterile Plantago lanceolata flowers. 1- $\mu \mathrm{m}$-thick transverse sections of fixed individual flowers were stained with toluidine blue and photographed under bright field microscopy. Single locules from representative stages of anther development are shown in panels a-e. a Microspore mother cells are formed and four anther wall layers are present (stage 5 of anther development). The tapetal cells are more vacuolated than in the hermaphrodites at the equivalent stage 5. b Microspore mother cells show evidence of preparation for meiosis (late stage 5 of anther development). The tapetal cells are much more vacuolated than in

\section{Discussion}

This study shows that a CMSI sterility factor affects anther development in MS flowers after four anther wall cell types have developed (stage 5 anther development). Cytology reveals cellular abnormalities in all four anther wall layers, the persistence and enlargement of middle layer and tapetal cells, and the failure of MMCs to complete meiosis. Apoptotic-PCD is detected in all four cell layers of the anther wall before the middle layer and tapetal cells become enlarged. hermaphrodite anthers at the equivalent stage. c-e Meiosis fails to complete, defective meiotic products accumulate within the locules. All cells in the anther wall become highly vacuolated. The middle layer and tapetal cells persist, and greatly enlarge and seem to crush the defective meiotic products within the locules. $\mathbf{f}$ Cross-section of a mature MS anther, all cells/tissues internal to the epidermis are collapsed. DMP defective meiotic products, $E$ epidermis, $E n$ endothecium, $M l$ middle layer, $M M C$ Microspore mother cell, $T$ tapetum. Scale bar $=20 \mu \mathrm{m}(\mathbf{a}), 10 \mu \mathrm{m}(\mathbf{b}), 20 \mu \mathrm{m}(\mathbf{c}-\mathbf{f})$

PCD occurs earlier in MS anthers than in fertile anthers and cell death progresses from the outer epidermal layer inwards to the tapetum. In angiosperms, male sterility programs can be initiated at any stage of stamen development; before organ initiation, early in organ development, pre-meiosis and post meiosis (reviewed by Diggle et al. 2011). Alterations in tapetal development are the most obvious and frequently recorded anther wall defects associated with all male sterility systems in flowering plants, including cytoplasmic male sterility (Balk and Leaver 2001; Li et al. 2004; Luo et al. 

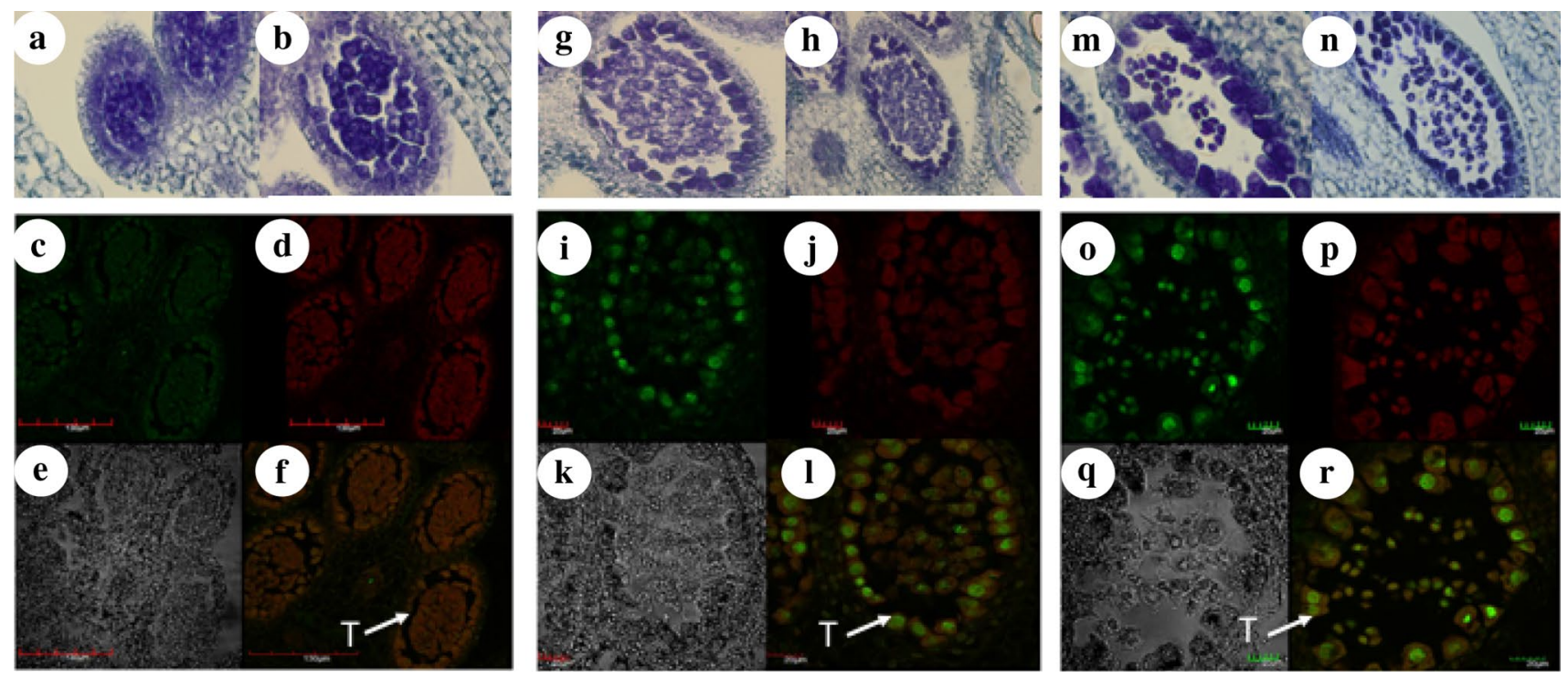

Fig. 4 PCD during anther development in hermaphrodite Plantago lanceolata flowers. 10- $\mu \mathrm{m}$-thick longitudinal sections of fixed inflorescence tissue were assayed for PCD using an in situ TUNEL assay. An entire transverse anther section is shown in panels $\mathbf{c}-\mathbf{f}$, single locule sections are shown in all other panels. a-f Pre-meiotic, stage 5 anther sections. g-l Stage 6 anther sections during meiosis. $\mathbf{m}-\mathbf{r}$ Post-meiotic, stage 7 anther sections. Top panels $(\mathbf{a}, \mathbf{b}, \mathbf{g}, \mathbf{h}, \mathbf{m}, \mathbf{n})$ are unassayed, toluidine blue-stained, sections viewed with bright field microscopy to help with anther staging. Bottom panels $(\mathbf{c}-\mathbf{f}, \mathbf{i}-\mathbf{l}, \mathbf{o}-\mathbf{r})$

2013), genic male sterility underlying sex determination in unisexual flowering plant taxa (Falasca et al. 2013; Moon and Hong 2015), and in environmental stress-induced male sterility (De Storme and Geelen 2014). The tapetum is in direct contact with the developing male gametophyte tissue within locules and this anther wall layer serves several functions: it is required for meiosis completion, it supports microspore development, it provides enzymes needed for the release of microspores from tetrads, and PCD of the tapetum supplies essential components needed for pollen-wall formation in fertile anthers (Parish and Li 2010). Both premature and delayed PCD of the tapetum has been shown to induce male sterility in many systems (Balk and Leaver 2001; Ku et al. 2003; Kawanabe et al. 2006; Li et al. 2006). However, close examination of sterile anther mutants in maize suggests that other anther wall layers may also contribute to the sterility process, perhaps mediated by more subtle cellular changes, like altering the timing or extent of anticlinal or periclinal cell divisions in anther wall layers and affecting cellular differentiation or signaling across the anther lobe (Egger and Walbot 2016; Walbot and Egger 2016). Thus, although we have designated MS anther wall layers based on their relative position (epidermis, endothecium, middle layer and tapetum), since there are no defining cell type markers for any anther wall cell types it is impossible to say if the are sections assayed for PCD using TUNEL. c, i, o Sections assessed for the green fluorescence of fluorescein. $\mathbf{d}, \mathbf{j}, \mathbf{p}$ Sections assessed for the red fluorescence of propidium iodide. e, $\mathbf{k}$, $\mathbf{q}$ Sections under bright field view. f, l, $\mathbf{r}$ Merged green and red fluorescence images. The TUNEL signal (fluorescein) fluoresces green in cell nuclei containing fragmented DNA and undergoing PCD. $\mathbf{l}, \mathbf{r}$ PCD is detected in tapetal cells after meiosis begins in hermaphrodite anthers. $T$ Tapetum. Scale bar $=130 \mu \mathrm{m}(\mathbf{c}-\mathbf{f}), 20 \mu \mathrm{m}(\mathbf{i}-\mathbf{l}, \mathbf{0}-\mathbf{r})$

correct cellular differentiation of cell types in each wall layer actually occurs in MS plants.

The MS anther morphology shows similarities to sterile anther morphologies described previously in a range of different male sterile contexts. Some other gynodioecious species, such as Persicaria amphibia (Polygonaceae) and several taxa of Hawaiian Bidens (Asteraceae), also follow a male sterility program that involves abnormal vacuolation of tapetal cells, early abortion of microsporogenesis, and radial enlargement of all layers of the locule wall especially the tapetum (Sun and Ganders 1987; Moon and Hong 2015). Within some functionally dioecious Cactaceae (Opuntia stenopetala and several Consolea species), the male abortion process involves tapetal abnormalities before meiosis, meiotic failure, a persistent middle layer, and a greatly hypertrophied tapetum (Strittmatter et al. 2006; Flores-Rentería et al. 2013). In barley, high temperature-induced male sterility correlates with abnormal vacuolization and hypertrophy of all four anther wall layers including the tapetum (Oshino et al. 2007). In Arabidopsis thaliana fat tapetum mutants, anther morphology is normal until the onset of meiosis after which the tapetum and middle layer become enlarged, both layers persist and microsporogenesis is aborted (Sanders et al. 1999). All of these studies are suggestive of other sporogenic tissues, not just the tapetum, being involved in 

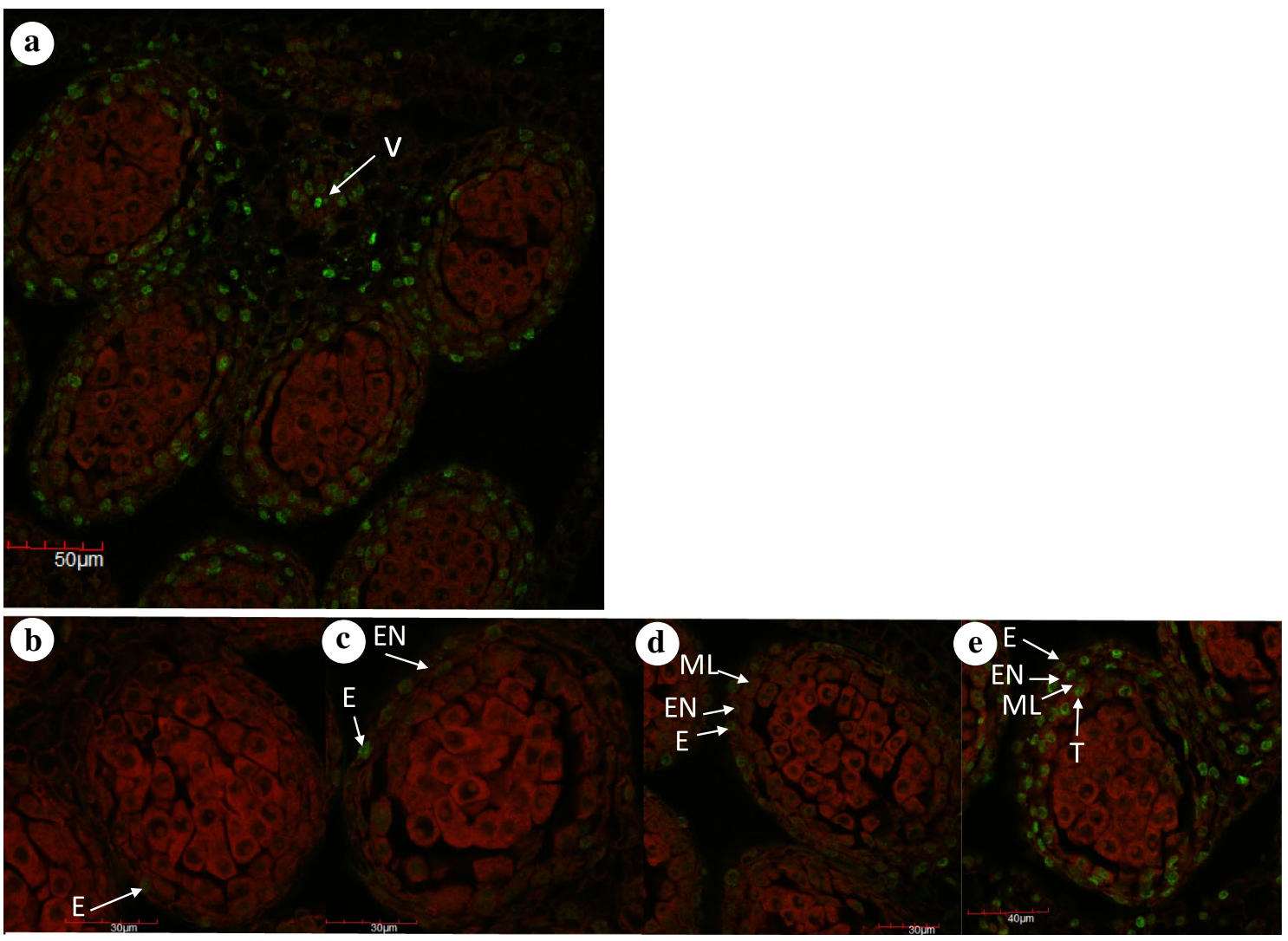

Fig. 5 PCD during anther development in male sterile Plantago lanceolata flowers. $10-\mu \mathrm{m}$-thick longitudinal sections of fixed inflorescence tissue were assayed for PCD using an in situ TUNEL assay. a-e Pre-meiotic, stage 5 anther sections. a Transverse section of an entire anther. b-e Transverse sections of a single locule. Sections were assessed for the green fluorescence of fluorescein and for the red

supporting MMC meiotic progression and the development of fertile pollen within anthers.

A complex gene regulatory network involved in pollen development is shared between $A$. thaliana and rice, suggesting a conserved developmental pathway throughout flowering plants (Gómez et al. 2015). In Arabidopsis, early tapetum development and function is controlled by the sequential activation of three transcription factor genes, DYSFUNCTIONAL TAPETUM 1 (DYTI), TAPETAL DEVELOPMENT and FUNCTION (TDF1), and ABORTED MICROSPORES $(A M S)$. In mutants defective in any of these genes $(d y t 1, t d f$ or $a m s$ ), anther development is normal until stage 5 after which vacuolated, swollen, tapetal cells are observed during meiosis and all of the mutants display a male sterile phenotype (Zhu et al. 2011). In $d y t 1$ mutants, tapetal cell abnormality is linked to failure of MMCs to complete meiosis and to produce microspores (Zhang et al. 2006), while in $t d f$ and ams mutants, meiosis is completed but microspores are not released (Zhu et al. 2011). In rice, mutations in the DYT1 homolog UNDEVELOPED TAPETUMI (UDTI) also fluorescence of propidium iodide, only merged green and red fluorescence images are shown. PCD is detected in all four layers of the anther wall before meiosis begins and proceeds from the epidermal layer inwards across the anther wall. $E$ Epidermis, $E N$ endothecium, $M L$ middle layer, $T$ tapetum, $V$ vascular tissue. Scale bar $=50 \mu \mathrm{m}(\mathbf{a})$, $30 \mu \mathrm{m}(\mathbf{b}-\mathbf{d}), 40 \mu \mathrm{m}(\mathbf{e})$

result in a defective tapetum with abnormal vacuolation, meiotic failure and male sterility (Jung et al. 2005; Zhang et al. 2006). One possible gene target of a signaling process initiated by male sterility-inducing factors could be a DYTI orthologue in the gynodioecious, functionally dioecious, and abiotic stress-sensitive taxa that share a similar sterile anther cytology.

Progressive PCD of anther wall cells has been described in both fertile and sterile contexts in several taxa. During fertile anther development in Lilium, PCD extends radially from the tapetum outwards to the epidermal layer (Varnier et al. 2005). In kiwifruit, the tapetum undergoes PCD first before expanding to the middle layer (Falasca et al. 2013) and in wheat, PCD occurs first in the tapetum before expanding to other external anther wall layers (Liu et al. 2018). In sterile anthers of some functionally dioecious taxa, PCD occurs in microspore mother cells and tapetal cells before extending to all four layers of the anther wall (Flores-Rentería et al. 2013; Hernández-Cruz et al. 2018). In the PET1CMS mutant in sunflower, PCD first occurs in tapetal cells 
and then extends to all other anther wall layers (Balk and Leaver 2001). These studies suggest that a cell death signal is first perceived and responded to by internal anther tissue (MMCs and/or tapetum) before being conveyed to the external cell layers of the anther and that this can occur during both fertile and sterile anther development. What is unusual about the Plantago MS sterility program is that the wave of PCD proceeds from the epidermis to the inner anther wall cell types, suggesting that in these anthers a cell death signal is first perceived and responded to by the epidermal cells before being conveyed inwards to cells in the other anther wall layers. Neighbor relationships are important in determining both the signaling source and the direction in which signals are transmitted across the anther lobe during development. The establishment of cell fate in anther walls is dependent on signals that emanate from both external domains (epidermal cells) and internal domains (meiotically competent cells) of lobe primordia. For example, pre-meiotic archesporial cells direct sub-epidermal cell fate and differentiation in the anther wall, while the epidermis affects cell specification in internal anther wall layers and meiotic progression of sporogenous cells within locules (reviewed by Walbot and Egger 2016). Thus, it may be that the direction cell death progression across the anther lobe is dependent on which signaling mechanism is disrupted (one progressing inwards or one progressing outwards) by any particular sterility factor.

Reactive oxygen species (ROS), although highly damaging to cells, can also act as concentration-dependent signaling molecules to determine the timing of PCD in plants. A temporal peak of ROS production in the tapetum correlates with the initiation and progression of tapetal PCD in several flowering plant species, and manipulating peroxide metabolism (genetically or pharmacologically) disrupts the normal timing of tapetal PCD resulting in male sterility (Chen and Liu 2014; Xie et al. 2014; Yu et al. 2017). In wild abortive CMS rice (CMS-WA), the mitochondrial sterility protein WA352 alters peroxide metabolism, specifically in the tapetum by interacting with the nuclear-encoded mitochondrial protein COX11 triggering ROS burst and premature death of the tapetum (Luo et al. 2013). ROS burst also correlates with plant PCD induced by several abiotic stress factors (Petrov et al. 2015). These studies demonstrate that different signaling inputs (both developmental and environmental) converge on the same output (ROS burst) to initiate PCD in plants. Thus, the progression of PCD seen in MS anthers is also likely triggered by anomalous ROS accumulation in anther cells in response to an as yet to be identified sterility factor.

In $\mathrm{H}$ anthers, cell death leads to complete degradation and rapid elimination of the tapetum (Fig. $2 \mathrm{f}-\mathrm{h}$ ), a process that shows similarities to autophagy-mediated PCD where both cell death and cell degeneration are linked. Autophagic cell death is characterized by the occurrence of double-membrane autophagosomes within the dying cells that remove the cell remnants. In rice, PCD of the tapetum (as determined by DNA fragmentation) is initiated at the tetrad stage of anther development ( $\mathrm{Li}$ et al. 2006) and autophagy occurs at the uninucleate stage of anther development (as determined by the presence of autophagosome-like structures, Kurusu et al. 2014). This indicates temporal separation of the cell death process and autophagy in rice anthers. The rice autophagy-defective mutant Osatg7-1 is male sterile and tapetal cell remnants are not cleared from the anther wall after PCD (Kurusu et al. 2014) indicating that autophagy is required to support male fertility in rice. In MS anthers, DNA fragmentation initiates a cell death pathway that generates highly vacuolated cells, followed by cell hypertrophy and prolonged cell retention, particularly of middle layer and tapetal cells. This process shows similarities to vacuole-mediated PCD which is generally associated with the growth of lytic vacuoles required for the digestion of cytoplasmic contents and self-clearance of dying cells, and with the retention of unprocessed cellular corpses. Vacuole-mediated PCD is considered to be a more generalized plant cell suicide system than autophagic cell death, and it is associated with both pathogen-induced (e.g. hypersensitive response) and developmental cell death in plants (Hatsugai et al. 2006). Diverse proteases, including vacuolar processing enzymes (VPEs), play a key role in vacuole-mediated PCD. In Arabidopsis, one such protease ( $\delta \mathrm{VPE}$ ) is expressed in two cell layers of the seed coat (ii2 and ii3) during early seed development and is required for the shrinkage and removal of these cell layers. In seeds of a $\delta v p e-1$ mutant, the cells in these seed coat layers not only persist but also appear much larger than in wild-type seeds (Nakaune et al. 2005). One possibility is that the cell death signal in MS anthers is involved in activating a more general, stress-related, cell death program in anther wall cells via a mechanism that might inhibit, or inactivate, VPE function in these cells. However, further studies will be required to investigate and distinguish between autophagy-mediated and/or vacuolemediated PCD in Plantago $\mathrm{H}$ and MS anther contexts.

Author contribution statement JN conceived and designed the research. MQ and ES carried out the phenotypic analyses. JN, MQ and ES performed the cytology. JN, TB and $\mathrm{GMcC}$ performed the cell death assays. JN wrote the manuscript. All authors read and approved the manuscript.

Acknowledgements We thank Dr. Ica Dix for help with confocal microscopy and photography, and Dr. Julie Kennedy for help with tissue embedding and ultramicrotome sectioning. This work was funded by an allocation received from the Department of Biology, Maynooth University. 


\section{References}

Balk J, Leaver CJ (2001) The PET1-CMS mitochondrial mutation in sunflower is associated with premature programmed cell death and cytochrome c release. Plant Cell 13:1803-1818

Chen L, Liu Y-G (2014) Male sterility and fertility restoration in crops. Annu Rev Plant Biol 65:579-606

Cui X, Wise RP, Schnable PS (1996) The $r f 2$ nuclear restorer gene of male-sterile T-cytoplasm maize. Science 272:1334-1336

de Haan AA, Mateman AC, VanDijk PJ, Van Damme JMM (1997a) New CMS types in Plantago lanceolata and their relatedness. Theor Appl Genet 94:539-548

de Haan AA, Koelewijn HP, Hundscheid MPJ, Van Damme JMM (1997b) The dynamics of gynodioecy in Plantago lanceolata L. II. Mode of action and frequencies of restorer alleles. Genetics 147:1317-1328

De Storme N, Geelen D (2014) The impact of environmental stress on male reproductive development in plants: biological processes and molecular mechanisms. Plant Cell Environ 37:1-18

Diggle PK, Di Stilio VS, Gschwend AR, Golenberg EM, Moore RC, Russell JRW, Sinclair JP (2011) Multiple developmental processes underlie sex differentiation in angiosperms. Trends Genet $27: 368-376$

Dufaÿ M, Champelovier P, Käfer J, Henry JP, Mousset S, Marais GAB (2014) An angiosperm-wide analysis of the gynodioecy-dioecy pathway. Ann Bot 114:539-548

Egger RL, Walbot V (2016) A framework for evaluating developmental defects at the cellular level: an example from ten maize anther mutants using morphological and molecular data. Dev Biol 419:26-40

Falasca G, D’Angeli S, Biasi R, Farrorini L, Matteucci M, Canini A, Altamura MM (2013) Tapetum and middle layer control male fertility in Actinidia deliciosa. Ann Bot 112:1045-1055

Feng X, Kaur AP, Mackenzie SA, Dweikat IM (2009) Substoichiometric shifting in the fertility reversion of cytoplasmic male sterile pearl millet. Theor Appl Genet 118:1361-1370

Flores-Rentería L, Orozco-Arroyo G, Cruz-García F, García-Campusano F, Alfaro I, Vázquez-Santana S (2013) Programmed cell death promotes male sterility in the functional dioecious Opuntia stenopetala (Cactaceae). Ann Bot 112:789-800

Fujii S, Toriyama K (2009) Suppressed expression of RETROGRADEREGULATED MALE STERILITY restores pollen fertility in cytoplasmic male sterile rice plants. Proc Natl Acad Sci USA 106:9513-9518

Gómez JF, Talle B, Wilson ZA (2015) Anther and pollen development: a conserved developmental pathway. J Integr Plant Biol $57: 876-891$

Hatsugai N, Kuroyanagi M, Nishimura M, Hara-Nishimura I (2006) A cellular suicide strategy of plants: vacuole-mediated cell death. Apoptosis 11:905-911

Henderson LB (1926) Floral anatomy of several species of Plantago. Am J Bot 13:397-405

Hernández-Cruz R, Barrón-Pacheco F, Sánchez D, Arias S, VázquezSantana S (2018) Functional dioecy in Echinocereus: ontogenetic patterns, programmed cell death, and evolutionary significance. Int J Plant Sci 179:257-274

Horn R, Gupa KJ, Colombo N (2014) Mitochondrion role in molecular basis of cytoplasmic male sterility. Mitochondrion 19:198-205

Hu J, Huang W, Huang Q, Qin X, Yu C, Wang L, Li S, Zhu R, Zhu Y (2014) Mitochondria and cytoplasmic male sterility in plants. Mitochondrion 19:282-288

Itabashi E, Iwata N, Fujii S, Kazama T, Toriyama K (2011) The fertility restorer gene, $R f 2$, for lead rice-type cytoplasmic male sterility of rice encodes a mitochondrial glycine-rich protein. Plant J 65:359-367
Ji C, Li H, Chen L, Xie M, Wang F, Chen Y, Liu YG (2013) A novel rice bHLH transcription factor, DTD, acts coordinately with TDR in controlling tapetum function and pollen development. Mol Plant 6:1715-1718

Jung KH, Han MJ, Lee YS, Kim YW, Hwang I, Kim MJ, Kim YK, Nahm BH, An G (2005) Rice Undeveloped Tapetuml is a major regulator of early tapetum development. Plant Cell 17:2705-2722

Kawanabe T, Ariizumi T, Kawai-Yamada M, Uchimiya H, Toriyama $\mathrm{K}$ (2006) Abolition of the tapetum suicide program ruins microsporogenesis. Plant Cell Physiol 47:784-787

Kim Y-J, Zhang D (2018) Molecular control of male fertility for crop hybrid breeding. Trends Plant Sci 23:53-65

Koch I, Alves DM, Souto LS (2018) Anther wall and pollen development in two species of Rauvolfia L. (Apocynaceae). Braz J Bot $41: 175-184$

Ku S, Yoon H, Suh H, Chung Y (2003) Male-sterility of thermosensitive genic male-sterile rice is associated with premature programmed cell death of the tapetum. Planta 217:559-565

Kurusu T, Koyano T, Hanamata S, Kubo T, Noguchi Y, Yagi C, Nagata N, Yamamoto T, Ohnishi T, Okazaki Y, Kitahata N, Ando D, Ishikawa M, Wada S, Miyao A, Hirochika H, Shimada H, Makino A, Saito K, Ishida H, Kinoshita T, Kurata N, Kuchitsu K (2014) OsATG7 is required for autophagy-dependent lipid metabolism in rice post-meiotic anther development. Autophagy 10:878-888

Landgren M, Zetterstrand M, Sundberg E, Glimelius K (1996) Alloplasmic male-sterile Brassica lines containing B. tournefortii mitochondria express an ORF 3' of the atp6 gene and a $32 \mathrm{kDa}$ protein. Plant Mol Biol 32:879-890

Li SQ, Wan CX, Kong J, Zhang ZJ, Li YS, Zhu YG (2004) Programmed cell death during microgenesis in a Honglian CMS line of rice is correlated with oxidative stress in mitochondria. Funct Plant Biol 31:369-376

Li N, Zhang D-S, Liu H-S, Yin C-S, Li X-X, Liang W-Q, Yuan Z, Xu B, Chu H-W, Wang J, Wen T-Q, Huang H, Luo D, Ma H, Zhang D-B (2006) The rice Tapetum Degeneration Retardation gene is required for tapetum degradation and anther development. Plant Cell 18:2999-3014

Liu Z, Shi X, Li S, Hu G, Zhang L, Song X (2018) Tapetal-delayed programmed cell death (PCD) and oxidative stress-induced male sterility of Aegilops uniaristata cytoplasm in wheat. Int J Mol Sci 19:1708

Luo D, Xu H, Liu Z, Guo J, Li H, Chen L, Fang C, Zhang Q, Bai M, Yao N, Wu H, Wu H, Ji C, Zheng H, Chen Y, Ye S, Li X, Zhao X, Li R, Liu Y-G (2013) A detrimental mitochondrial-nuclear interaction causes cytoplasmic male sterility in rice. Nat Genet 45:573-577

Matsuhira H, Kagami H, Kurata M, Kitazaki K, Matsunaga M, Hamaguchi Y, Hagihara E, Ueda M, Harada M, Muramatsu A, YuiKurino R, Taguchi K, Tamagake H, Mikami T, Kubo T (2012) Unusual and typical features of a novel restorer-of-fertility gene of sugar beet (Beta vulgaris L.). Genetics 192:1347-1358

Moon HK, Hong SP (2015) Morphological traits of gynodioecious Persicaria amphibia (Polygonaceae). Phytotaxa 219:133-143

Murayama K, Yahara T, Terachi T (2004) Variation of female frequency and cytoplasmic male-sterility gene frequency among natural gynodioecious populations of wild radish (Raphanus sativus). Mol Ecol 13:2459-2464

Naghloo S, Classen-Bockhoff R (2016) Gradual inhibition of staminate structures results in various degrees of male sterility in Knautia arvensis. Int J Plant Sci 177:608-617

Nakaune S, Yamada K, Kondo M, Kato T, Tabata S, Nishimura M, Hara-Nishimura I (2005) A vacuolar processing enzyme, $\delta$ VPE, is involved in seed coat formation at the early stage of seed development. Plant Cell 17:876-887

Olff H, Kuiper D, Van Damme JMM, Kuiper PJC (1989) Gynodioecy in Plantago lanceolata. VI. Functions of cytokinins in growth, 
development, and reproduction of two sex types. Can J Bot 67:2765-2769

Onodera Y, Arakawa T, Yui-Kurino R, Yamamoto MP, Kitazaki K, Ebe S, Matsunaga M, Taguchi K, Kuroda Y, Yamashita S, Sakai T, Kinoshita T, Mikami T, Kubo T (2015) Two male sterility-inducing cytoplasms of beet (Beta vulgaris) are genetically distinct but have closely related mitochondrial genomes: implication of a substoichiometric mitochondrial DNA molecule in their evolution. Euphytica 206:365-379

Oshino T, Abiko M, Saito R, Ichiishi E, Endo M, Kawagishi-Kobayashi M (2007) Premature progression of anther early developmental programs accompanied by comprehensive alterations in transcription during high-temperature injury in barley plants. Mol Genet Genomics 278:31-42

Papini A, Mosti S, Brighigna L (1999) Programmed-cell-death events during tapetum development of angiosperms. Protoplasma 207:213-221

Parish RW, Li SF (2010) Death of a tapetum: a programme of developmental altruism. Plant Sci 178:73-89

Petrov V, Hille J, Mueller-Roeber B, Gechev TS (2015) ROS-mediated abiotic stress-induced programmed cell death in plants. Front Plant Sci 6:69

Renner SS (2014) The relative and absolute frequencies of angiosperm sexual systems: dioecy, monoecy, gynodioecy, and an updated online database. Am J Bot 101:1588-1596

Sanders PM, Bui AQ, Weterings K, McIntire KN, Hsu YC, Lee PY, Truong MT, Beals TP, Goldberg RB (1999) Anther developmental defects in Arabidopsis thaliana male-sterile mutants. Sex Plant Reprod 11:297-322

Sarria R, Lyznik A, Vallejos CE, Mackenzie SA (1998) A cytoplasmic male sterility-associated mitochondrial peptide in common bean is post-translationally regulated. Plant Cell 10:1217-1228

Scott RJ, Spielman M, Dickinson HG (2004) Stamen structure and function. Plant Cell 16:S46-S60

Shaya F, Gaiduk S, Keren I, Shevtsov S, Zemah H (2012) Expression of mitochondrial gene fragments within the tapetum induce male sterility by limiting the biogenesis of the respiratory machinery. $\mathrm{J}$ Integr Plant Biol 54:115-130

Sloan DB, Müller K, McCauley DE, Taylor DR, Štorchová H (2012) Intraspecific variation in mitochondrial genome sequence, structure, and gene content in Silene vulgaris, an angiosperm with pervasive cytoplasmic male sterility. New Phytol 196:1228-1239

Städler T, Delph LF (2002) Ancient mitochondrial haplotypes and evidence for intragenic recombination in a gynodioecious plant. Proc Natl Acad Sci USA 99:11730-11735

Stone JD, Koloušková P, Sloan DB, Štorchová H (2017) Non-coding RNA may be associated with cytoplasmic male sterility in Silene vulgaris. J Exp Bot 68:1599-1612
Štorchová H, Müller K, Lau S, Olson MS (2012) Mosaic origins of a complex chimeric mitochondrial gene in Silene vulgaris. PLoS One 7:e30401

Strittmatter LI, Negrón-Ortiz V, Hickey JR (2006) Comparative microsporangium development in male-fertile and male-sterile flowers of Consolea (Cactaceae): when and how does pollen abortion occur. Grana 45:81-100

Sun M, Ganders FR (1987) Microsporogenesis in male-sterile and hermaphroditic plants of nine gynodioecious taxa of Hawaiian Bidens (Asteraceae). Am J Bot 74:209-217

Touzet P (2012) Mitochondrial genome evolution and gynodioecy. Adv Bot Res 63:71-98

Van Damme JMM, Van Delden W (1982) Gynodioecy in Plantago lanceolata L. I. Polymorphism for plasmon type. Heredity 49:303-318

Varnier A-L, Mazeyrat-Gourbeyre F, Sangwan RS, Clément C (2005) Programmed cell death progressively models the development of anther sporophytic tissues from the tapetum and is triggered in pollen grains during maturation. J Struct Biol 152:118-128

Walbot V, Egger RL (2016) Pre-meiotic anther development: cell fate specification and differentiation. Annu Rev Plant Biol 67:365-395

Wang M, Hoekstra S, van Bergen S, Lamers GEM, Oppedijk BJ, van der Heijden MW, de Priester W, Schilperoort RA (1999) Apoptosis in developing anthers and the role of ABA in this process during androgenesis in Hordeum vulgare L. Plant Mol Biol 39:489-501

Xie HT, Wan ZY, Li S, Zhang Y (2014) Spatiotemporal production of reactive oxygen species by NADPH oxidase is critical for tapetal programmed cell death and pollen development in Arabidopsis. Plant Cell 26:2007-2023

Yamamoto MP, Shinada H, Onodera Y, Komaki C, Mikami T, Kubo $\mathrm{T}$ (2008) A male sterility-associated mitochondrial protein in wild beets causes pollen disruption in transgenic plants. Plant J 54:1027-1036

Yu S-X, Feng Q-N, Xie H-T, Li S, Shang Y (2017) Reactive oxygen species mediate tapetal programmed cell death in tobacco and tomato. BMC Plant Biol 17:76

Zhang W, Sun Y, Timofejeva L, Chen C, Grossniklaus Y, Ma H (2006) Regulation of Arabidopsis tapetum development and function by DYSFUNCTIONAL TAPETUM1 (DYT1) encoding a putative bHLH transcription factor. Development 133:3085-3095

Zhu J, Lou Y, Xu X, Yang Z-N (2011) A genetic pathway for tapetum development and function in Arabidopsis. J Integr Plant Biol 53:892-900 